\title{
Bovinos Mestiços Alimentados com Diferentes Proporções de Volumoso:Concentrado. 2. Efeito sobre a Ingestão de Nutrientes ${ }^{1}$
}

\author{
Flávio Dutra de Resende ${ }^{2}$, Augusto César de Queiroz ${ }^{3}$, José Victor de Oliveira2, \\ José Carlos Pereira ${ }^{3}$, Antonio Bento Mâncio ${ }^{3}$
}

\begin{abstract}
RESUMO - O objetivo deste trabalho foi avaliar os efeitos da relação volumoso: concentrado sobre a ingestão dos nutrientes de 25 novilhos mestiços, com $310 \mathrm{~kg}$ peso vivo (PV) médio inicial. Foram usadas cinco rações à base de feno de capim-tanzânia e concentrado, em diferentes proporções de volumoso:concentrado (85:15; 70:30; 55:45; 40:60; e 25:75). Observou-se efeito quadrático do nível de concentrado sobre a ingestão de matéria seca (MS), matéria orgânica (MO), proteína bruta (PB) e energia bruta (EB), com ingestões máxima para MS de 2,87\% PV; MO, 118g/kg ${ }^{0,75}$ e 2,7\% PV; PB, 1,52 kg/dia; 18,2 g/ $/ \mathrm{kg}^{0,75}$; e 0,42\% PV e EB, $536 \mathrm{Kcal} / \mathrm{kg}^{0,75}$, para os níveis 39, 44, 42, 43, 39, 38 e 46\% de concentrado, respectivamente. Observou-se efeito quadrático para ingestão de MS digestível (MSD), MO digestível (MOD), proteína digestível (PD) e energia digestível (ED), com ingestões máximas para MSD de 7,07; 83,8; e 1,91; MOD, 6,91; 81,4, e 1,86; e PD, 1,13; 13,4; e 0,31, em kg/dia, g/kg0,75 e \% PV, para os níveis de 52, 49, 48, 54, 51, 50, 41, 28 e 37\% de concentrado, respectivamente. Para ED, as ingestões máximas foram de 30,6 Mcal/dia e $356 \mathrm{kcal} / \mathrm{kg}^{0,75}$, para os níveis de 62 e $57 \%$ de concentrado na dieta, respectivamente. A maximização da ingestão de nutrientes digestíveis para a máxima eficiência de utilização ocorreu com níveis de ingestão de FDN variando de 1,25 a 1,02\% PV para novilhos mestiços.
\end{abstract}

Palavras-chave: bovinos de corte, ingestão, nutrientes, níveis de concentrado

\section{Feedlot Confined Crossbreed Steers Fed with Different Forage to Concentrate Ratios. 2. Effect on the Nutrients Intake}

\begin{abstract}
The objective of this work was to evaluate the effects of the forage to concentrate ratio in the nutrient intake by 25 crossbred steers with initial $310 \mathrm{~kg} \mathrm{LW}$. Five full fed diets based on tanzaniagrass hay and concentrate, with different forage to concentrate ratio $(85: 15,70: 30,55: 45 ; 40: 60$; and 25:75) were used. A quadratic effect was observed for the concentrate level in the diet on the intake of dry matter (DM), organic matter (OM), crude protein (CP) and, gross energy (GE), with a maximum intake for DM, 2.87\% PV; OM, $118 \mathrm{~g} / \mathrm{w}^{0,75}$ e $2.7 \% \mathrm{PV}$; CP, $1.52 \mathrm{~kg} /$ day; $18.2 \mathrm{~g} / \mathrm{w}^{0,75}$; and $0.42 \% \mathrm{PV}$ e GE, $536 \mathrm{Kcal} / \mathrm{w}^{0,75}$, for the levels of 39; 44, 42; 43; 39 , e 38 e $46 \%$ of concentrate, respectively. A quadratic effect was observed for the digestible dry matter (DDM), digestible organic matter (DOM), digestible protein (DP) and digestible energy (ED), with a maximum intake for DDM of 7.07; 83.8; and 1.91; DOM, 6.91; 81.4, and 1.86; and DP, $1.13 ; 13.4$; e 0.31 , in $\mathrm{kg} / \mathrm{day}, \mathrm{g} / \mathrm{w}^{0,75}$ and $\% \mathrm{LW}$, respectively, for the levels of 52, 49, 48, 54, 51, 50, 41, 28 e $37 \%$ of concentrate. For DE, the maximum intake were $30.6 \mathrm{Mcal} /$ day and $356 \mathrm{kcal} / \mathrm{w}^{0,75}$, for the levels of 62.0 and $57.0 \%$ of concentrate, respectively. The maximization of the digestible nutrient intake for the maximum efficiency of nutrient utilization occurred with the intake of NDF ranged from 1.25 to $1.02 \% \mathrm{LW}$ for crossbred steers
\end{abstract}

Key Words: beef cattle, concentrate level, intake, nutrient

\section{Introdução}

Existem poucas informações disponíveis em relação aos níveis de volumoso e concentrado nas dietas de bovino de corte, principalmente referentes a volumosos de baixa qualidade. Estudos de como essa relação influi na ingestão de nutrientes, bem como na utilização dos alimentos, são fundamentais para formular e manipular as dietas utilizadas, visando a máxima eficiência da mesma.

O termo ingestão voluntária refere-se à quantidade máxima de matéria seca (MS) ingerida pelo animal espontaneamente. A capacidade de um alimento ser ingerido pelo animal depende da ação de vários fatores que interagem em diferentes situações de alimentação, comportamento animal e meio ambiente (THIAGO e GILL, 1990). A predição da ingestão em ruminantes é extremamente importante e difícil, devido às interações que ocorrem entre o animal e a dieta, existindo poucos dados disponíveis para subsidiar o uso de equações (FORBES, 1995).

CONRAD et al.(1964) indicaram que a ingestão

\footnotetext{
1 Parte da tese de doutorado do primeiro autor junto ao Dept ${ }^{\circ}$ de Zootecnia da UFV.

2 Pesquisador Científico do Instituto de Zootecnia. Ext. Exper. de Zootecnia de Colina, Cx Postal 35, CEP 14770-000, Colina - SP

3 Professor do Dept $^{\circ}$ de Zootecnia da Universidade Federal de Viçosa, Viçosa - MG.
} 
alimentar é dependente das características do animal e da dieta; se for limitada pela capacidade física do animal, quando a dieta contém altas proporções de fibra em detergente neutro (FDN), a ingestão tornase uma função das características da dieta. Dessa forma, o animal consome alimento até atingir a capacidade máxima de ingestão de FDN, que passa inibir a ingestão, havendo, assim, limite de distensão ruminal, que determina a interrupção da ingestão voluntária (MERTENS, 1987, 1988). CONRAD et al. (1964) relataram que, em razão de a ingestão voluntária ser dependente das características químicas e físicas da dieta, é importante incorporar, nas equações de predição, algumas medidas de qualidade do alimento para melhorar a acurácia das mesmas em prever a ingestão. Para esses autores, quando se trabalha com dietas de baixa qualidade, a ingestão é predita com mais acurácia por fatores que descrevem o limite físico da ingestão - digestibilidade da dieta, output fecal (índice de capacidade física) e peso vivo. Em dietas de melhor qualidade, a ingestão seria predita por fatores que descrevem fatores metabólicos como a demanda fisiológica do animal (MERTENS, 1983). A primeira característica que influencia esta relação é a digestibilidade. $\mathrm{O}$ animal consome alimento para manter ingestão constante de energia, e a ingestão de MS diminui com o aumento da digestibilidade. O fator que determina a saciedade, controlando a ingestão, nesse caso, é a densidade calórica da ração (VAN SOEST, 1965).

Pelo exposto, a ingestão e a digestibilidade podem estar positiva ou negativamente correlacionadas entre si, dependendo da qualidade da dieta (VAN SOEST, 1994; MERTENS, 1985). A correlação é positiva quando se utilizam dietas contendo alta proporção de volumoso de baixa qualidade, pois o volume ocupado pela fração de baixa digestibilidade reduz a ingestão. O esvaziamento do trato gastrintestinal é dado pelo aumento na taxa de passagem; assim, a ingestão é inversamente relacionada com o conteúdo de FDN da dieta. Quando o volume da dieta é limitante, os animais não são capazes de consumir quantidades suficientes de MS para atender suas necessidades energéticas, o que implica em queda no desempenho. Por outro lado, a ingestão e a digestibilidade são negativamente correlacionadas quando se utilizam dietas de alta qualidade, em que a fração fibrosa (FDN) é pequena e, provavelmente, não influi na ingestão, que será controlada pelo requerimento energético do animal.

$\mathrm{O}$ ponto de transição entre o controle físico e fisiológico, em que a ingestão de MS é máxima, tem sido estudado em vários trabalhos. Este ponto de transição não é fixo, ocorrendo na interseção entre o nível de FDN da ração e a curva de requerimento do animal. Assim, o ponto em que o nível de FDN da ração deixa de limitar fisicamente a ingestão é determinado, primariamente, pelo nível de produção do animal, que é função do seu potencial genético (NATIONAL RESEARCH COUNCIL - NRC, 1988; NUTT et al., 1980).

Estudos que verificam a influência de diferentes relações volumoso:concentrado sobre a ingestão são escassos no Brasil, existindo bastante controvérsias na literatura quanto ao efeito provocado pelo enchimento do trato gastrointestinal sobre a ingestão, ao se utilizarem dietas de baixa qualidade, com teor elevado de fibra em detergente neutro. O estabelecimento de parâmetros da composição da dieta, rotineiramente medido em laboratório, é fundamental no sentido de poder estimar, previamente, a capacidade de ingestão do animal. Em virtude de a fibra em detergente neutro ser o componente da dieta que mais se relaciona com a ocupação de espaço no trato gastrintestinal, muitos trabalhos conduzidos em condições brasileiras têm sido desenvolvidos para se relacionar a capacidade de ingestão de determinada dieta com o conteúdo de fibra em detergente neutro da mesma.

Em face do exposto, o presente trabalho teve por objetivo estudar os efeitos de diferentes proporções volumoso:concentrado, utilizando-se cinco níveis de fibra em detergente neutro, sobre a ingestão dos nutrientes por bovinos mestiços alimentados em regime de confinamento.

\section{Material e Métodos}

Na avaliação da ingestão voluntária dos nutrientes, foram utilizados 25 bovinos mestiços machos (5/8 europeu/zebu), castrados aos sete meses, com peso vivo médio inicial de $310 \mathrm{~kg}$ e, aproximadamente, 24 meses de idade, mantidos confinados em baias individuais com piso cimentado, medindo $4 \times 6 \mathrm{~m}$, sendo $2 / 3$ da área cobertos e 1/3 restante, descobertos (solário). As baias eram providas de comedouro e bebedouro individuais. Cinco dietas experimentais, constituídas de feno de capim-tanzânia (Panicum maximum, cv tanzânia) moído, fubá de milho, farelo de soja, uréia, fosfato bicálcico, calcário calcítico, sal comum e mistura mineral, foram formuladas segundo as normas do NRC (1996). As dietas experimentais apresentaram proporção volumoso:concentrado de $85: 15$; 
272 Rev. bras. zootec.

70:30; 55:45; 40:60 e 25:75, com níveis decrescentes de fibra em detergente neutro (FDN) de 65,$9 ; 56,4$; 47,$5 ; 38,9$; e $30,1 \%$, respectivamente, na base da matéria seca (MS). Os teores de matéria seca, proteína bruta, fibra em detergente neutro, fibra em detergente ácido, energia bruta e matéria orgânica do feno e dos concentrados utilizados na formulação das diferentes rações encontram-se na Tabela 1.

A composição percentual dos ingredientes nas rações e a composição química das rações experimentais são apresentadas na Tabela 2.

Os animais passaram por um período de adaptação às instalações e dietas experimentais de 28 dias, dando início a fase experimental de 84 dias. Finalizada a adaptação dos animais, estes foram pesados no início e final das fases experimentais, após jejum prévio de 16 horas. No período experimental, pesaram-se a ração fornecida e as sobras deixadas pelos animais diariamente.

As rações foram fornecidas à vontade, individualmente, conforme cada tratamento, duas vezes/dia, às 8 e $16 \mathrm{~h}$, controlando-se a ingestão durante todo o período de coleta, procurando-se manter as sobras entre 5 e $10 \%$ do total fornecido. Diariamente, pela manhã, antecedendo ao fornecimento das rações, retiraram-se as sobras, pesando-as e anotando-se os dados em planilhas apropriadas de controle diário de fornecido e sobras. As sobras foram então amostradas na proporção de 5\% do total das mesmas, acondicionadas em sacolas plásticas devidamente etiquetadas e armazenadas em freezer. Semanalmente, amostraram-se o feno fornecido e os diferentes concentrados utilizados, acondicionando-se as amostras em sacolas plásticas e guardadas em freezer. Ao final do período experimental, as amostras de feno e concentrados fornecidos, bem como as amostras de sobras de cada animal, foram retiradas do freezer, descongeladas em temperatura ambiente e homogeneizadas manualmente. Para cada animal, fez-se uma amostra composta das sobras do período, secando-a em estufa de ventilação forçada a $60 \pm 5^{\circ} \mathrm{C}$, por 48 horas, para determinação da amostra pré-seca. Da mesma forma procedeu-se com o feno e concentrados fornecidos. Posteriormente, as mesmas foram moídas em moinho tipo "Willey", com peneira de 30 "mesh", acondicionadas em vidro para posteriores análises químicas.

As análises químicas foram realizadas no Laboratório de Nutrição Animal do Departamento de Zootecnia da Universidade Federal de Viçosa e na Estação Experimental de Zootecnia de Colina. Realizaram-se as determinações da matéria seca, matéria orgânica, fibra em detergente neutro, fibra em detergente ácido, proteína bruta e energia bruta, conforme metodologias descritas por SILVA (1990).

A ingestão de MS digestível (MSD), MO digestível (MOD), proteína digestível (PD) e energia digestível (ED) baseou-se nos dados de digestibilidade dos nutrientes obtidos por RESENDE et al. (2001).

Usou-se o delineamento experimental inteiramente casualizado com cinco tratamentos e cinco repetições. As análises estatísticas das variáveis estudadas foram interpretadas por análise de variância e de regressão, utilizando-se o programa SAS (1992) e os coeficientes de regressão foram comparados pelo teste t, a $5 \%$ de probabilidade.

Tabela 1 - Composição química (\% da MS) e energia bruta (Mcal $/ \mathrm{kg})$ do feno e dos concentrados usados nas diferentes dietas 1 Table 1 - Chemical composition (\%DM) and gross energy (Mcal/kg) of the hay and concentrates used in the differents diets

\begin{tabular}{|c|c|c|c|c|c|c|}
\hline \multirow[t]{2}{*}{ Item } & \multirow[t]{2}{*}{$\begin{array}{l}\text { Feno } \\
\text { Hay }\end{array}$} & \multicolumn{5}{|c|}{$\begin{array}{l}\text { Nível de concentrado na dieta } \\
\text { Concentrate level in the diet }\end{array}$} \\
\hline & & 15 & 30 & 45 & 60 & 75 \\
\hline $\begin{array}{l}\text { Matéria seca } \\
\text { Dry matter }\end{array}$ & 83,83 & 81,20 & 81,81 & 81,58 & 81,80 & 81,79 \\
\hline $\begin{array}{l}\text { Proteína bruta } \\
\text { Crude protein }\end{array}$ & 7,86 & 46,93 & 29,22 & 22,22 & 19,09 & 16,28 \\
\hline $\begin{array}{l}\text { Fibra em detergente neutro } \\
\text { Neutral detergent fiber }\end{array}$ & 74,66 & 14,66 & 12,71 & 13,41 & 14,41 & 14,82 \\
\hline $\begin{array}{l}\text { Fibra em detergente ácido } \\
\text { Acid detergentfiber }\end{array}$ & 44,74 & 6,15 & 5,31 & 5,11 & 5,41 & 4,89 \\
\hline $\begin{array}{l}\text { Energia bruta } \\
\text { Gross energy }\end{array}$ & 3,99 & 4,18 & 4,23 & 4,30 & 4,30 & 4,32 \\
\hline $\begin{array}{l}\text { Matéria orgânica } \\
\text { Organic matter }\end{array}$ & 91,66 & 95,93 & 96,77 & 97,07 & 96,66 & 96,66 \\
\hline
\end{tabular}


Tabela 2 - Composição percentual dos ingredientes (\%MN) e teores de nutrientes (\%MS) das diferentes dietas Table 2 - Percentage composition of the ingredients(\% as fed) and nutrient contents (\%DM) in the different diets

\begin{tabular}{|c|c|c|c|c|c|}
\hline \multirow[t]{2}{*}{$\begin{array}{l}\text { Ingrediente } \\
\text { Ingredient }\end{array}$} & \multicolumn{5}{|c|}{$\begin{array}{l}\text { Nível de concentrado na dieta } \\
\text { Concentrate level in the diet }\end{array}$} \\
\hline & 15 & 30 & 45 & 60 & 75 \\
\hline & \multicolumn{5}{|c|}{$\begin{array}{l}\text { Composição percentual } \\
\text { Percent composition }\end{array}$} \\
\hline \multicolumn{6}{|l|}{ Feno de capim-tanzânia } \\
\hline $\begin{array}{l}\text { Fubá de milho } \\
\text { Corn meal }\end{array}$ & 7,06 & 21,52 & 35,8 & 47,01 & 60,06 \\
\hline $\begin{array}{l}\text { Farelo de soja } \\
\text { Soybean meal }\end{array}$ & 6,68 & 7,24 & 8,73 & 12,02 & 14,03 \\
\hline $\begin{array}{l}\text { Uréia } \\
\text { Urea }\end{array}$ & 1,17 & 0,99 & 0,74 & 0,36 & 0,07 \\
\hline \multirow[t]{2}{*}{$\begin{array}{l}\text { Mistura mineral } \\
\text { Mineral mix }\end{array}$} & 0,10 & 0,25 & 0,35 & 0,60 & 0,85 \\
\hline & \multicolumn{5}{|c|}{$\begin{array}{l}\text { Teor de nutriente } \\
\text { Nutrient content }\end{array}$} \\
\hline $\begin{array}{l}\text { Matéria seca }(\%) \\
\text { Dry matter }\end{array}$ & 83,45 & 83,23 & 82,83 & 82,49 & 82,15 \\
\hline $\begin{array}{l}\text { Proteína bruta }(\%) \\
\text { Crude protein }\end{array}$ & 13,72 & 14,27 & 14,30 & 14,59 & 14,17 \\
\hline $\begin{array}{l}\text { Fibra em detergente neutro (\%) } \\
\text { Neutral detergent fiber }\end{array}$ & 65,90 & 56,39 & 47,51 & 38,87 & 30,06 \\
\hline $\begin{array}{l}\text { Fibra em detergente ácido (\%) } \\
\text { Acid detergentfiber }\end{array}$ & 43,40 & 36,75 & 30,18 & 23,75 & 16,72 \\
\hline $\begin{array}{l}\text { Matéria orgânica }(\%) \\
\text { Organic matter }\end{array}$ & 92,28 & 93,17 & 94,06 & 94,63 & 95,39 \\
\hline $\begin{array}{l}\text { Energia bruta (Mcal/kg MS) } \\
\text { Gross energy }\end{array}$ & 4,02 & 4,06 & 4,13 & 4,17 & 4,23 \\
\hline $\begin{array}{l}\text { Energia digestível (Mcal/kg MS) } \\
\text { Digestible energy }\end{array}$ & 2,16 & 2,47 & 2,71 & 2,76 & 2,94 \\
\hline
\end{tabular}

1 À base de: (Based in) cloreto de sódio (sodium chloride) nos níveis de (in the levels of) 87,2; 35,7; 25,2; 17,4; e 12,4\%), fosfato bicálcico (dicalcium phosfate) $(11,5 ; 38,0 ; 0,0 ; 0,0 ;$ e 0,0), calcário calcítico (limestone) $(0,0 ; 25,0 ; 73,5 ; 81,3 ;$ e 86,3), sulfato de zinco (zinc sulfate) (1\%), sulfato de cobre (copper sulfate) $(0,25 \%)$, iodato de potássio (potassium lodate) $(0,03 \%)$ e sulfato de cobalto (cobalto sulfate) $(0,03 \%)$ para as rações com (for the diets with) $15,30,45,60$ e $75 \%$ de concentrado (concentrate), respectivamente (respectively).

2 Valor calculado em função da energia bruta e do coeficiente de digestibilidade da energia bruta obtido por REZENDE et al. 2000 (no presente estudo (Calculated value in function of the gross energy and the coefficienty of digestibility obtained by REZENDE et al. 2000).

\section{Resultados e Discussão}

Os resultados médios de ingestão de nutrientes, coeficientes de variação (CV) e equações de regressão ajustadas (ER) são mostrados na Tabela 3. Ao se realizarem as análises de regressão da ingestão de MS e MO, em função do nível de concentrado na dieta, constatou-se que não houve efeito significativo do teor de concentrado sobre a ingestão de MS, expressa em $\mathrm{kg} / \mathrm{dia} \mathrm{e} \mathrm{g} / \mathrm{kg} 0,75$, sendo os valores médios obtidos de 10,09 e 120,12, respectivamente, e MO, expressa em kg/dia, de 9,49. Observou-se, também, que para EB, expressa em Mcal/dia, não houve efeito significativo dos níveis de concentrado na dieta sobre a ingestão da mesma, sendo o valor médio obtido de 43,3 Mcal/dia. Já no caso da ingestão de
MS, expressa em \%PV; ingestão de MO, expressa em g/kg ${ }^{0,75}$ e \%PV; e ingestão de PB, expressa em $\mathrm{kg} / \mathrm{dia}, \mathrm{g} / \mathrm{kg}^{0,75}$ e \%PV, as equações de regressão em função do teor de concentrado na ração revelaram efeito quadrático $(\mathrm{P}<0,05)$ do teor de concentrado sobre a ingestão de MS, MO e PB, o mesmo sendo observado para ingestão de EB, expressa em kcal $/ \mathrm{kg}^{0,75}$.

Ao derivar as equações, foram estimados os pontos de máximo para ingestão de MS, em 2,87\% PV, correspondentes ao teor de concentrado na dieta de $39 \%$, e para ingestão da MO, a máxima ingestão estimada foi de 118 e 2,70 , expressa em $\mathrm{g} / \mathrm{kg}^{0,75}$ e $\% \mathrm{PV}$, correspondentes a 44 e $42 \%$ de concentrado na dieta, respectivamente. Para PB, expressa em kg/ dia, $\mathrm{g} / \mathrm{kg} 0,75$ e \% PV, a ingestão máxima estimada foi de 1,$52 ; 18,2 ;$ e 0,42 , correspondente ao uso de 43,39 
274 Rev. bras. zootec.

Tabela 3 - Médias e equações de regressão ajustadas (ER) para ingestão de matéria seca (MS), matéria orgânica (MO), proteína bruta (PB), fibra em detergente neutro (FDN) e fibra em detergente ácido (FDA) expressas em $\mathrm{kg} / \mathrm{dia}$, gramas por unidade de tamanho metabólico $\left(\mathrm{g} / \mathrm{kg}^{0,75}\right)$ e porcentagem do peso vivo (\%PV) e energia bruta (EB), expressa em Mcal/dia e $\mathrm{Kcal} / \mathrm{kg}^{0,75}$, das diferentes dietas

Table 3 - Means and fitted regression equations (RE) for the intake of dry matter (DM), crude protein (CP), neutral detergent fiber (NDF) and acid detergent fiber (ADF), expressed in $\mathrm{kg} /$ day, grams per metabolic weight $\left(\mathrm{g} / \mathrm{w}^{.75}\right)$ and percentage of live weight (\%LW) and gross energy, expressed in Mcal/day e $\mathrm{kcal} / \mathrm{w}^{75}$, of the different diets

\begin{tabular}{|c|c|c|c|c|c|c|c|}
\hline \multirow[t]{2}{*}{ Item } & \multicolumn{5}{|c|}{$\begin{array}{l}\text { Nível de concentrado na dieta } \\
\text { Concentrate level in the diet }\end{array}$} & \multirow[t]{2}{*}{$\mathrm{CV}$} & \multirow[t]{2}{*}{ ER } \\
\hline & 15 & 30 & 45 & 60 & 75 & & \\
\hline MS (kg/dia) & 9,64 & 9,94 & 10,02 & 11,36 & 9,38 & 12,17 & $\hat{\mathrm{Y}}=10,09$ \\
\hline $\begin{array}{l}\text { MS }\left(\mathrm{g} / \mathrm{kg}^{0,75}\right) \\
\text { MS (\%PV) }\end{array}$ & $\begin{array}{r}119,69 \\
2,77\end{array}$ & $\begin{array}{r}119,71 \\
2,76\end{array}$ & $\begin{array}{r}119,82 \\
2,74\end{array}$ & $\begin{array}{r}132,07 \\
3,00\end{array}$ & $\begin{array}{r}106,58 \\
2,40\end{array}$ & $\begin{array}{l}8,97 \\
8,35\end{array}$ & $\begin{array}{l}\hat{Y}=120,12 \\
1\end{array}$ \\
\hline $\begin{array}{l}\text { MO (kg/dia) } \\
\text { MO (g/kg0,75) } \\
\text { MO (\%PV) } \\
\text { PB (kg/dia) } \\
\text { PB (g/kg0,75) } \\
\text { PB (\%PV) }\end{array}$ & $\begin{array}{r}8,90 \\
110,51 \\
2,56 \\
1,35 \\
16,79 \\
0,39\end{array}$ & $\begin{array}{r}9,29 \\
111,89 \\
2,58 \\
1,43 \\
17,27 \\
0,40\end{array}$ & $\begin{array}{r}9,46 \\
113,11 \\
2,59 \\
1,44 \\
17,23 \\
0,39\end{array}$ & $\begin{array}{r}10,77 \\
125,25 \\
2,84 \\
1,60 \\
18,59 \\
0,42\end{array}$ & $\begin{array}{r}8,94 \\
101,70 \\
2,29 \\
1,16 \\
13,19 \\
0,30\end{array}$ & $\begin{array}{r}12,17 \\
8,96 \\
8,32 \\
13,75 \\
10,51 \\
9,61\end{array}$ & $\begin{array}{l}\hat{Y}=9,49 \\
2 \\
3 \\
4 \\
5 \\
6\end{array}$ \\
\hline $\begin{array}{l}\text { EB (Mcal } / \mathrm{dia}) \\
\text { EB }\left(\text { Kcal } / \mathrm{kg}^{0,75}\right)\end{array}$ & $\begin{array}{r}40,08 \\
496,92\end{array}$ & $\begin{array}{r}42,03 \\
505,05\end{array}$ & $\begin{array}{r}43,10 \\
514,63\end{array}$ & $\begin{array}{r}49,37 \\
571,66\end{array}$ & $\begin{array}{r}41,44 \\
469,03\end{array}$ & $\begin{array}{r}12,00 \\
8,74\end{array}$ & $\begin{array}{l}\hat{Y}=43,28 \\
7\end{array}$ \\
\hline $\begin{array}{l}\text { FDN (kg/dia) } \\
\text { FDN (g/kg0,75) } \\
\text { FDN (\%PV) }\end{array}$ & $\begin{array}{r}6,25 \\
77,70 \\
1,80\end{array}$ & $\begin{array}{r}5,43 \\
65,42 \\
1,51\end{array}$ & $\begin{array}{r}4,51 \\
53,92 \\
1,23\end{array}$ & $\begin{array}{r}4,41 \\
51,31 \\
1,16\end{array}$ & $\begin{array}{r}2,96 \\
33,63 \\
0,76\end{array}$ & $\begin{array}{r}11,67 \\
8,69 \\
8,18\end{array}$ & $\begin{array}{l}\hat{Y}=4,78 \\
8 \\
9\end{array}$ \\
\hline $\begin{array}{l}\text { FDA }(\mathrm{kg} / \mathrm{dia}) \\
\text { FDA }\left(\mathrm{g} / \mathrm{kg}^{0,75}\right) \\
\text { FDA }(\% \mathrm{PV})\end{array}$ & $\begin{array}{r}4,18 \\
51,95 \\
1,20 \\
\end{array}$ & $\begin{array}{r}3,60 \\
43,41 \\
1,00 \\
\end{array}$ & $\begin{array}{c}2,92 \\
34,88 \\
0,80 \mathrm{c} \\
\end{array}$ & $\begin{array}{r}2,75 \\
31,98 \\
0,73 \\
\end{array}$ & $\begin{array}{r}1,74 \\
19,81 \\
0,44 \\
\end{array}$ & $\begin{array}{r}10,96 \\
8,04 \\
7,45 \\
\end{array}$ & $\begin{array}{l}\hat{\mathrm{Y}}=3,09 \\
10 \\
11\end{array}$ \\
\hline \multicolumn{6}{|c|}{$1 \hat{\mathrm{Y}}=2,45529+0,02094^{* *} c-0,000266^{* *} \mathrm{c}^{2}$} & \multicolumn{2}{|c|}{$\mathrm{R}^{2}=21,83$} \\
\hline \multicolumn{6}{|c|}{$2 \hat{\mathrm{Y}}=94,93775+1,03735^{* *} c-0,01168^{* *} \mathrm{c}^{2}$} & \multicolumn{2}{|c|}{$\mathrm{R}^{2}=17,36$} \\
\hline \multicolumn{6}{|c|}{$3 \hat{\mathrm{Y}}=2,2239+0,02253^{* *} c-0,0002673^{* *} c^{2}$} & \multicolumn{2}{|c|}{$\mathrm{R}^{2}=20,54$} \\
\hline \multicolumn{6}{|c|}{$4 \hat{\mathrm{Y}}=1,025+0,02344^{* *} c-0,000274^{* *} \mathrm{c}^{2}$} & \multicolumn{2}{|c|}{$\mathrm{R}^{2}=24,56$} \\
\hline \multicolumn{6}{|c|}{$5 \hat{Y}=13,3238+0,24793^{* *} c-0,003163^{* *} c^{2}$} & \multicolumn{2}{|c|}{$\mathrm{R}^{2}=40,31$} \\
\hline \multicolumn{6}{|c|}{$6 \hat{\mathrm{Y}}=0,313625+0,005324^{* *} c-0,0000698^{* *} c^{2}$} & \multicolumn{2}{|c|}{$\mathrm{R}^{2}=45,61$} \\
\hline \multicolumn{6}{|c|}{$7 \hat{\mathrm{Y}}=424,044+4,8360^{* *} c-0,0522^{* *} c^{2}$} & \multicolumn{2}{|c|}{$\mathrm{R}^{2}=18,32$} \\
\hline \multicolumn{6}{|c|}{$8 \hat{\mathrm{Y}}=86,4028-0,6483^{* *} c$} & \multicolumn{2}{|c|}{$\mathrm{R}^{2}=89,99$} \\
\hline \multicolumn{6}{|c|}{$9 \hat{\hat{Y}}=2,0178-0,01605^{* *} c$} & \multicolumn{2}{|c|}{$\mathrm{R}^{2}=91,66$} \\
\hline \multicolumn{6}{|c|}{$10 \hat{\mathrm{Y}}=58,4811-0,4712^{* *} c$} & \multicolumn{2}{|c|}{$R^{2}=93,25$} \\
\hline \multicolumn{6}{|c|}{$11 \hat{\mathrm{Y}}=1,3607-0,01146^{* *} c$} & \multicolumn{2}{|c|}{$\mathrm{R}^{2}=94,47$} \\
\hline
\end{tabular}

e $38 \%$ de concentrado na dieta, respectivamente. No caso da EB, a ingestão máxima estimada foi de $536 \mathrm{kcal} / \mathrm{kg}^{0,75}$, correspondente ao uso de $46 \%$ de concentrado na dieta. ARAÚJO et al. (1998), trabalhando com bezerros mestiços de holandeses em crescimento, alimentados com feno de coastcross e concentrado, em cinco proporções de 90:10; 55:45; 40:60; 25:75; e 10:90, também verificaram efeito quadrático dos níveis de concentrado da dieta sobre a ingestão de MS e MO. Entretanto, BÜRGER et al. (2000), também utilizando bezerros holandeses alimentados com feno de coastcross e concentrado, nos níveis de 70:30; 55:45; 40:60; 25:75 e 10:90\% na dieta, não verificaram influência destes níveis na ingestão de MS e MO, quando expressa em $\mathrm{kg} / \mathrm{dia}$, sendo os valores médios obtidos de 4,11 e 3,87 kg/dia, respectivamente. Porém, quando a ingestão de MS e MO foi expressa em $\%$ PV e $\mathrm{g} / \mathrm{kg}^{0,75}$, observou-se diminuição linear na ingestão, em função do aumento dos níveis de concentrado na dieta. RODRIGUES et al. (1996) também observaram efeito quadrático na ingestão de MS e MO, à medida que se elevou o teor de concentrado na ração. Os pontos de máximo para ingestão de MS e MO, obtidos por esses autores, 
expressos em $\mathrm{g} / \mathrm{kg}^{0,75}$ e \%PV, corresponderam aos teores de concentrados na dieta de 58,55, 59 e 56\%, respectivamente. DUTRA et al. (1997), utilizando com dietas de alta e baixa fibra, encontraram maior ingestão de MS e MO nas rações de baixa fibra, atribuindo a menor ingestão de MS e MO, para as rações com alta fibra, à limitação provocada pelo enchimento do rúmen-retículo e da baixa taxa de passagem, que normalmente ocorrem em rações com estas características. RESENDE et al. (1994) verificaram relação linear entre a ingestão de MS e o nível de FDN da ração, não sendo possível determinar o ponto de máxima ingestão de MS, o mesmo foi observado por GONÇALVES (1991) e MORAN (1985), ao utilizarem rações contendo diferentes proporções volumoso:concentrado. Contrariamente, CARVALHO et al. (1997), avaliando rações com diferentes proporções volumoso:concentrado (20 a 70\%), verificaram não haver influência dos níveis de concentrados na dieta sobre a ingestão de MS e MO, expressa em $\mathrm{kg} / \mathrm{dia}$ e \% PV, tendo obtido os valores médios para MS de 3,56 e 1,80 e MO de 3,39 e 1,70, respectivamente. RIBEIRO (1997), trabalhando com bezerros holandeses alimentados com feno de coast-cross e quatro níveis de concentrado, de 45, 60, 75 e 90\%, na dieta, verificou não haver influência dos níveis de concentrado na dieta sobre a ingestão de MS, expressa em kg/dia, g/ $\mathrm{kg}^{0,75}$ e \%PV, sendo os valores médios obtidos de 3,97; 92,2; e 2,65, respectivamente.

Para proteína, RODRIGUES et al. (1996) verificaram que a ingestão de PB e PD, expressa em $\mathrm{g} / \mathrm{kg}^{0,75}$, aumentou ao se variar o nível de concentrado na dieta de 12,5 a $50 \%$. Esses autores atribuíram o aumento na ingestão de proteína ao incremento na ingestão de MS, uma vez que não havia grandes variações nos teores de PB das rações, encontrando ingestões variando de 7,07 a 13,56 g/ $\mathrm{kg}^{0,75} \mathrm{de} \mathrm{PB/dia}$ e de 4,57 a $9,17 \mathrm{~g} / \mathrm{kg}^{0,75} \mathrm{de} \mathrm{PD} / \mathrm{dia}$. No presente estudo, a ingestão de $\mathrm{PB}$ apresentou resposta quadrática em função dos níveis de concentrado na dieta, estimando-se ingestões máximas de $1,52 \mathrm{~kg} /$ dia, $18,2 \mathrm{~g} / \mathrm{kg}^{0,75} \mathrm{e} 0,42 \% \mathrm{PV}$, correspondentes ao uso de 43,39 e $38 \%$ de concentrado na dieta, respectivamente. Tal comportamento na ingestão de PB é atribuído à variação na ingestão de MS, uma vez que as dietas continham níveis semelhantes de PB. Já CARVALHO et al. (1997), trabalhando com diferentes proporções de volumoso:concentrado, não encontraram influência dos níveis de concentrado da dieta sobre a ingestão de $\mathrm{PB}$, tendo obtido ingestão média de 0,46 e 0,23 , expressa em kg/dia e \%PV, respecti- vamente. CARVALHO et al. (1997) e RODRIGUES et al. (1996) avaliaram dietas isoprotéicas com 12\% $\mathrm{PB}$, o mesmo ocorrendo no presente estudo, com $14 \%$ PB. A maior ingestão de PB obtida neste estudo, quando comparada aos trabalhos anteriormente citados, pode ser atribuída à maior concentração de PB na dieta e maior ingestão de MS obtida nos diversos tratamentos. CARVALHO et al. (1997) obtiveram ingestão média de MS de 1,80\% PV; RODRIGUES et al. (1996), ingestão máxima de 2,44\%PV; e no presente estudo a ingestão máxima estimada foi de $2,87 \% \mathrm{PV}$, o que acarretou ingestão diária de PB bem acima da requerida pelos animais. Vale ressaltar que se pretendia trabalhar com rações isoprotéicas contendo, em média, $12 \% \mathrm{~PB}$, porém utilizou-se um feno de melhor qualidade, o que elevou o teor protéico na dieta total, promovendo assim maior ingestão de PB. $\mathrm{Na}$ Tabela 3, verifica-se que a ingestão de MS reduziu sensivelmente, quando se utilizou $75 \%$ de concentrado na dieta. A variação individual na ingestão diária de MS nos animais recebendo $75 \%$ de concentrado na dieta foi elevada, possivelmente, devido a problemas como acidose subclínica.

Segundo MERTENS (1983), para perfeito balanço microbiano no rúmen, é importante a manutenção de quantidades mínimas de fibra na ração, que é necessária para manter apropriada fermentação no rúmen e, também, estimular a adequada ruminação e salivação, indispensáveis à manutenção da fermentação e à prevenção de distúrbios ruminais. A dieta com $75 \%$ de concentrado na dieta continha $30 \%$ de FDN e $17 \%$ FDA e estes valores, embora tenham sido superiores ao mínimo de 25\% recomendado de FDN na dieta total (SNIFFEN, 1987), podem não ter sido suficientes para evitar os transtornos digestivos ocorridos. As análises de regressão da ingestão de FDN e FDA, expressa em g/kg 0,75 e \%PV, em função do teor de concentrado na dieta, revelaram decréscimo contínuo na ingestão de FDN e FDA, com o aumento do teor de concentrado na dieta. CARVALHO et al. (1997), avaliando dietas com diferentes proporções de volumoso:concentrado de 20 a $70 \%$ de concentrado, em que os teores de FDN da ração expressos na base da MS total da ração variaram de 68,1 a $37,0 \%$, verificaram diminuição linear na ingestão de FDN com o aumento da proporção de concentrado na dieta, tendo a ingestão variado de 0,99 a $0,58 \%$ PV. Vários autores (RIBEIRO, 1997; BÜRGER et al., 2000, 1998; e ARAÚJO et al., 1998), trabalhando com bezerros que receberam dietas com diferentes proporções de volumoso:concentrado, também veri- 
276 Rev. bras. zootec.

ficaram efeito linear decrescente na ingestão de FDN e FDA, à medida que se elevaram os níveis de concentrado na dieta, entretanto, RODRIGUES et al. (1996) não constaram diferenças na ingestão de FDN, expressa em g/ $/ \mathrm{kg}^{0,75}$ e \% PV, à medida que se elevou o teor de concentrado na dieta de 12,5 para $50 \%$, concluindo que o teor de fibra das rações teria sido o fator limitante na ingestão, uma vez que houve aumento na ingestão de MS e MO, à medida que se elevou a proporção de concentrado da ração com redução do teor de FDN. DUTRA et al. (1997), também, encontraram ingestão semelhante de FDN, ao avaliarem dietas de alta e baixa fibra, observando

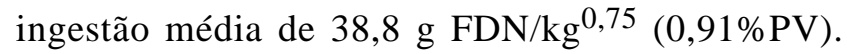
RESENDE et al. (1994), avaliando dietas com diferentes proporções volumoso:concentrado e níveis decrescentes de FDN, observaram que não houve diferença na ingestão de FDN entre as rações, encontrando valor médio de $55,0 \mathrm{~g} / \mathrm{kg}^{0,75}$ e 1,27\% PV, mostrando que os animais ingeriram a capacidade máxima de ingestão de FDN, a qual, provavelmente, regulou a ingestão voluntária. Segundo VAN SOEST (1994), se a parede celular foi limitante da ingestão, ela terá máximo de ingestão constante. Para este autor, a natureza quadrática entre a ingestão de MS e a concentração de energia na dieta pode ser vista como indicativo de que há ponto transição entre os mecanismos físicos e fisiológicos que controlam a ingestão. Neste ponto, observa-se a máxima ingestão de MS pelo animal. Observa-se na Figura 1 que a

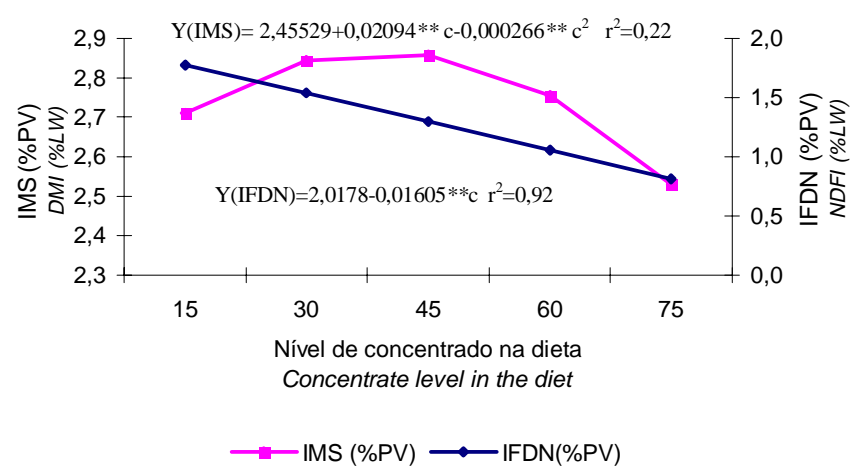

Figura 1 - Ingestão de matéria seca (IMS) e de fibra em detergente neutro (IFDN), expressas em \%PV, em função das proporções de concentrado utilizados na dieta.

Figure 1 - Intake of dry matter (DMI) and neutral detergent fiber(NDFI), expressed in $\% L W$, in function of the concentrate levels used in the diet. máxima ingestão de MS foi de 2,87\%PV, correspondente ao teor de concentrado na dieta de $39 \%$. Assim, a ingestão de FDN, para o nível de $39 \%$ de concentrado na dieta, em que ingestão de MS foi máxima, foi de $1,39 \% \mathrm{PV}$, superior ao encontrado por RESENDE et al. (1994), de 1,27\%PV.

$\mathrm{Na}$ Tabela 4, são apresentados os valores médios de ingestão de matéria seca digestível (MSD), matéria orgânica digestível (MOD) e proteína digestível (PD), expressos em kg/dia, $\mathrm{g} / \mathrm{kg}^{0,75}$ e \%PV, e energia digestível (ED), expressa em Mcal/dia e $\mathrm{kcal} / \mathrm{kg}^{0,75}$. Ao se realizarem as análises de regressão da ingestão de MSD, MOD e PD, expressa em kg/dia, $\mathrm{g} / \mathrm{kg}^{0,75}$ e \%PV, e ED, expressa em Mcal/dia e kcal/ $\mathrm{kg}^{0,75}$, em função do teor de concentrado na dieta, constatou-se efeito quadrático significativo do teor de concentrado sobre a ingestão de MSD, MOD, PD e ED.

Ao derivar as equações, foram estimados os pontos de máxima ingestão de MSD, MOD e PD. A proporção estimada de concentrado na dieta que propiciou a máxima ingestão, expressa em $\mathrm{kg} / \mathrm{dia}$, $\mathrm{g} / \mathrm{kg}^{0,75}$ e $\% \mathrm{PV}$, para MSD foi de 52, 49 e $48 \%$; MOD, de 54, 51 e $50 \%$; e PD, de 41,28 e $37 \%$, respectivamente. Para ED, expressa em Mcal/dia e $\mathrm{kcal} / \mathrm{kcal}^{0,75}$, a proporção estimada de concentrado foi de 62 e 57\%, respectivamente. Para estes níveis de concentrado na dieta, a ingestão máxima estimada, expressa em kg/dia, g/kg0,75 e \%PV, foi, para MSD, de 7,07; 83,8; e 1,91; para MOD, de 6,91; 81,4; e 1,86; e para $\mathrm{PD}$, de 1,$13 ; 13,4$; e $0,31 \%$, respectivamente. A ingestão máxima estimada para ED, expressa em $\mathrm{Mcal} / \mathrm{dia}$ e $\mathrm{kcal} / \mathrm{kg}^{0,75}$, foi de 30,6 e 356 , respectivamente.

Estimando a ingestão de FDN que maximizou a ingestão de MSD, expressa em $\mathrm{kg} / \mathrm{dia}, \mathrm{g} / \mathrm{kg}^{0,75} \mathrm{e}$ $\% \mathrm{PV}$, verificaram-se ingestões de 1,18; 1,23; e 1,25, respectivamente. Para MOD, expressa nestas mesmas bases, verificaram-se ingestões de FDN da ordem de 1,$15 ; 1,20$; e 1,21 , respectivamente. No caso da ED, expressa em Mcal/dia e kcal $/ \mathrm{kg}^{0,75}$, a ingestão máxima estimada de FDN foi de 1,02 e 1,10. O NRC (1988) sugere ingestão ótima de FDN de $1,2 \pm 0,1 \% \mathrm{PV}$ para gado leiteiro. Porém, para gado de corte, estes valores não estão definidos. Observa-se que a maioria dos valores estimados de ingestão de FDN, obtidos neste estudo, encontra-se na faixa de ingestão ótima de FDN recomendada pelo NRC (1988), de 1,2 $\pm 0,1 \%$ PV (Figura 2).

CONRAD et al. (1964) mostraram que, quando o animal se encontra sob regulação física da ingestão, a ingestão de energia aumenta com o valor nutritivo 
RESENDE et al.

Tabela 4 - Médias e equações de regressão ajustadas (ER) para ingestão de matéria seca digestível (MSD), matéria orgânica digestível (MOD), proteína digestível (PD), expressas em kg/dia, gramas por unidade de tamanho metabólico (g/ $\mathrm{kg}^{0,75}$ ) e porcentagem do peso vivo (\%PV) e energia digestível (ED), expressa em Mcal/dia e $\mathrm{kcal} / \mathrm{kg}^{0,75}$, das diferentes dietas

Table 4 - Means and fitted regression equations (RE) for the intake of digestible dry matter (DDM), digestible organic matter (DOM) digestible protein (DCP) expressed in $\mathrm{kg} /$ day, grams per metabolic weight $\left(\mathrm{g} / \mathrm{w}^{0,75}\right)$ and percentage of live weight $(\% \mathrm{LW})$ and digestible energy (DE) expressed in Mcal/day e $\mathrm{kcal} / \mathrm{w}^{75}$, of the different diets

\begin{tabular}{|c|c|c|c|c|c|c|c|}
\hline \multirow[t]{2}{*}{ Item } & \multicolumn{5}{|c|}{$\begin{array}{l}\text { Nível de concentrado na dieta } \\
\text { Concentrate level in the diet }\end{array}$} & \multirow[t]{2}{*}{$\mathrm{CV}$} & \multirow[t]{2}{*}{$\mathrm{ER}$} \\
\hline & 15 & 30 & 45 & 60 & 75 & & \\
\hline $\operatorname{MSD}(\mathrm{kg} / \mathrm{dia})$ & 5,32 & 6,08 & 6,73 & 7,64 & 5,95 & 12,72 & 1 \\
\hline $\operatorname{MSD}\left(\mathrm{kcal} / \mathrm{kg}^{0,75}\right)$ & 66,03 & 73,17 & 80,53 & 88,87 & 67,66 & 9,54 & 2 \\
\hline $\operatorname{MSD}(\% \mathrm{PV})$ & 1,53 & 1,69 & 1,84 & 2,02 & 1,52 & 8,99 & 3 \\
\hline $\operatorname{MOD}(\mathrm{kg} / \mathrm{dia})$ & 5,14 & 5,96 & 6,63 & 7,34 & 6,13 & 11,85 & 4 \\
\hline $\operatorname{MOD}\left(\mathrm{kcal} / \mathrm{kg}^{0,75}\right)$ & 63,85 & 71,82 & 79,23 & 85,33 & 69,69 & 8,43 & 5 \\
\hline $\operatorname{MOD}(\% \mathrm{PV})$ & 1,48 & 1,66 & 1,81 & 1,93 & 1,57 & 7,67 & 6 \\
\hline $\mathrm{PD}(\mathrm{kg} / \mathrm{dia})$ & 0,99 & 1,05 & 1,07 & 1,15 & 0,80 & 13,64 & 7 \\
\hline $\mathrm{PD}\left(\mathrm{g} / \mathrm{kg}^{0,75}\right)$ & 12,33 & 12,66 & 12,81 & 13,40 & 9,09 & 10,37 & 8 \\
\hline $\mathrm{PD}(\% \mathrm{PV})$ & 0,28 & 0,29 & 0,29 & 0,30 & 0,21 & 9,37 & 9 \\
\hline ED (Mcal/dia) & 21,53 & 25,54 & 28,31 & 32,70 & 28,78 & 11,82 & 10 \\
\hline $\mathrm{ED}\left(\mathrm{kcal} / \mathrm{kg}^{0,75}\right)$ & 266,99 & 306,82 & 338,01 & 378,61 & 325,74 & 8,27 & 11 \\
\hline \multicolumn{6}{|c|}{$1 \hat{\mathrm{Y}}=3,2097+0,14864^{* *} c-0,00143 * * \mathrm{c}^{2}$} & \multicolumn{2}{|c|}{$\mathrm{R}^{2}=46,01$} \\
\hline \multicolumn{6}{|c|}{$2 \hat{\mathrm{Y}}=42,2075+1,68183^{* *} c-0,01716^{* *} \mathrm{c}^{2}$} & \multicolumn{2}{|c|}{$\mathrm{R}^{2}=53,21$} \\
\hline \multicolumn{6}{|c|}{$3 \hat{\mathrm{Y}}=0,99296+0,03801^{* *} c-0,000396 * * c^{2}$} & \multicolumn{2}{|c|}{$\mathrm{R}^{2}=54,47$} \\
\hline \multicolumn{6}{|c|}{$4 \hat{\mathrm{Y}}=3,2539+0,13493^{* *} c-0,001243 * * \mathrm{c}^{2}$} & \multicolumn{2}{|c|}{$\mathrm{R}^{2}=49,90$} \\
\hline \multicolumn{6}{|c|}{$5 \hat{\mathrm{Y}}=42,51558+1,528699^{* *} c-0,01503 * * c^{2}$} & \multicolumn{2}{|c|}{$\mathrm{R}^{2}=58,24$} \\
\hline \multicolumn{6}{|c|}{$6 \hat{\hat{Y}}=1,0005+0,03446^{* *} c-0,0003467 * * c^{2}$} & \multicolumn{2}{|c|}{$\mathrm{R}^{2}=60,42$} \\
\hline \multicolumn{6}{|c|}{$7 \hat{\mathrm{Y}}=0,72179+0,019585^{* *} c-0,0002375 * 5^{2}$} & \multicolumn{2}{|c|}{$\mathrm{R}^{2}=33,84$} \\
\hline \multicolumn{6}{|c|}{$8 \hat{\mathrm{Y}}=9,4442+0,20829 * *-0,002719 * * c^{2}$} & \multicolumn{2}{|c|}{$\mathrm{R}^{2}=51,51$} \\
\hline \multicolumn{6}{|c|}{$9 \hat{\hat{Y}}=0,22625+0,0043055^{* *} c-0,000058 * * c^{2}$} & \multicolumn{2}{|c|}{$\mathrm{R}^{2}=56,56$} \\
\hline \multicolumn{6}{|c|}{$10 \hat{\mathrm{Y}}=13,8907+0,5414 * * c-0,0043788 * * c^{2}$} & \multicolumn{2}{|c|}{$\mathrm{R}^{2}=58,28$} \\
\hline \multicolumn{6}{|c|}{$11 \hat{\mathrm{Y}}=179,9466+6,1814 * * c-0,0543 * * c^{2}$} & \multicolumn{2}{|c|}{$\mathrm{R}^{2}=65,98$} \\
\hline
\end{tabular}

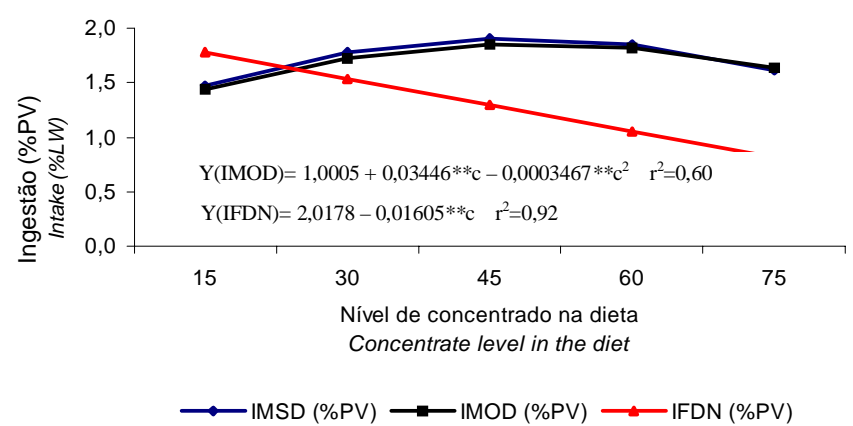

Figura 2 - Ingestão de matéria seca digestível (IMSD), matéria orgânica digestível (IMOD) e fibra em detergente neutro (IFDN), expressas em \%PV, em função das proporções de concentrado na dieta.

Figure 2 - Intake of digestible dry matter(DDMI), digestible organic matter(DOMI) and neutral detergent fiber(NDFI), expressed as $\% L W$, in function of the concentrate levels in the diet. da dieta e, dessa forma, a distensão ruminal é o principal mecanismo regulador da saciedade. Dietas à base de forragem enquadram-se, normalmente, neste caso, sendo a ingestão diretamente ligada ao valor nutritivo dessa dieta. Entretanto, quando a adição de concentrado melhora o valor nutritivo da dieta, a ingestão de energia aumenta até determinado ponto, ponto de transição entre o controle físico e fisiológico e, a partir daí, permanece constante. Nesse caso, o animal consegue ingerir energia suficiente para atender sua demanda fisiológica. No presente estudo, esperava-se atingir um platô na ingestão de energia, à medida que se elevou o teor de concentrado na dieta, o que não ocorreu, provavelmente, em função da redução na ingestão de matéria seca dos 
278 Rev. bras. zootec.

animais que receberam a dieta contendo $75 \%$ de concentrado. Observa-se que a ingestão máxima de energia digestível, expressa em Mcal/dia e kcal/ $\mathrm{kg}^{0,75}$, ocorreu ao se utilizarem 62 e $57 \%$ de concentrado na dieta, respectivamente, presumindo-se que nesta faixa estaria o ponto de transição entre o controle físico e fisiológico da ingestão. Pode-se inferir que a máxima ingestão de matéria seca, matéria orgânica e energia bruta foi obtida, ao se utilizar $60 \%$ de concentrado na dieta. WALDO (1986), comentando os dados obtidos por Montgomery e Baumgardt (1965a), verificou ingestão constante de energia $\left(250 \mathrm{kcal} / \mathrm{kg}^{0,75}\right)$ para ração peletizada de alta qualidade à base de alfafa-concentrado, evidenciando que os animais ingeriram para atender seu requerimento energético. CARVALHO et al. (1997) obteveram conclusão semelhante, avaliando dietas com diferentes proporções de volumoso:concentrado, tendo obtido ingestão constante de nutrientes digestíveis totais (NDT) de 2,29 kg/dia, reforçando a hipótese de que a ingestão de MS havia sido regulada pela demanda energética dos animais. Já RODRIGUES et al. (1996), trabalhando com diferentes proporções de volumoso:concentrado na dieta, verificaram que, à medida que o teor de concentrado na ração foi elevado de 12,5 para $37,5 \%$, ocorreu aumento na ingestão de energia digestível e matéria orgânica digestível. Acréscimos no teor de concentrado na dieta de 37,5 para $50 \%$ não resultaram em aumentos significativos na ingestão de MOD e ED. As análises de regressão realizadas por esses autores revelaram efeito quadrático do teor de concentrado da ração sobre a ingestão de MOD e ED e os pontos de máximo obtidos para ingestão de MOD, expressa em $\mathrm{g} / \mathrm{kg}^{0,75}$ e \% PV, corresponderam aos teores de concentrado na dieta de 61 e $58 \%$, respectivamente, os quais foram superiores aos do presente estudo. Para ED, expressa em $\mathrm{kcal} / \mathrm{kg}^{0,75}$, o ponto de máxima ingestão obtido por RODRIGUES et al. (1996) correspondeu ao uso de $51 \%$ de concentrado na ração, sendo inferior ao do presente estudo.

As crescentes ingestões de MSD, MOD e ED observadas com o aumento do teor de concentrado na dieta, porém sem haver diferenças na ingestão de matéria seca, matéria orgânica e energia bruta, em $\mathrm{kg} / \mathrm{dia}$, são atribuídas, provavelmente, à melhor digestibilidade da MS, MO e EB. Isso ocorreu, provavelmente, em função do efeito associativo positivo do concentrado sobre a digestibilidade da MS, MO e EB da dieta, respectivamente.

\section{Conclusões}

Os níveis de concentrado na dieta afetaram a ingestão dos nutrientes, observando-se resposta quadrática, em função do aumento dos níveis de concentrado na dieta.Este tipo de resposta indica a existência de níveis ótimos de inclusão de concentrados ou volumoso para a máxima eficiência de utilização dos nutrientes.

A maximização da ingestão de nutrientes digestíveis ocorreu com níveis de ingestão de fibra em detergente neutro, variando de 1,25 a 1,02\% PV, portanto, para bovinos de corte, a ingestão ótima de FDN para o máximo desempenho encontra-se na faixa recomendada pelo NRC para bovinos de leite, de $1,2 \pm 0,1 \% \mathrm{PV}$.

\section{Referências Bibliográficas}

ARAÚJO, G.G.L., COELHO DA SILVA, J.F., VALADARES FILHO, S.C. et al. 1998. Consumo e digestibilidade total dos nutrientes de dietas contendo diferentes níveis de volumoso, em bezerros. R. Bras. Zootec., 27(2):345-354.

BULL, L.S., BAUMGARDT, B.R., CLANCY, M. 1976. Influence of calorie density on energy intake by dairy cows. J. Dairy Sci., 59(6):1078-1086.

BÜRGER, P.J., PEREIRA, J.C., COELHO DA SILVA, J.F. et. al. 2000. Consumo e digestibilidade aparente total e parcial em bezerros holandeses alimentados com dietas contendo diferentes níveis de concentrado. Rev. bras. zootec., 29(1):206-214.

CARVALHO, A.U., VALADARES FILHO, S.C., COELHO DA SILVA, J.F. et al. 1997. Níveis de concentrado em dietas de zebuínos. 1. Consumo e digestibilidade. R. Bras. Zootec., 26(5):986-995.

CONRAD, H.R., PRATT, A.D., HIBBS, J.W. 1964. Regulation of feed intake in dairy cows. I- Change in importance of physical and physiological factors with increasing digestibility. J. Dairy Sci., 47(1):54-62.

DUTRA, A.R., QUEIROZ, A.C., PEREIRA, J.C. et al. 1997. Efeitos dos níveis de fibra e das fontes de proteínas sobre o consumo e digestão dos nutrientes em novilhos. R. Bras. Zootec., 26(4):787-796.

FORBES, J.M. 1995. Voluntary food intake and diet selection by farm animals. Madison: CAB International. 532p.

GONÇALVES, L.C., COELHO DA SILVA, J.F., ESTEVÃO, M.M. et. al. 1991.Consumo e digestibilidade da matéria seca e da energia em zebuínos e taurinos, seus mestiços e bubalinos. R. Soc. Bras. Zootec., 20(4):384-395.

MERTENS, D.R. Using neutral detergent fiber to formulate dairy rations and estimate the net energy content of feeds. In: CORNELL NUTRITION CONFERENCE, 1983, Ithaca. Proceedings... Ithaca: Cornell University, 1983. p.60-68.

MERTENS, D.R. Factors influencing feed intake in lactating cows: from theory to application using neutral detergent fiber. In: NUTRITION CONFERENCE, 46, 1985, Athens. Proceedings... Athens: University of Georgia, 1985. p.1-18.

MERTENS, D.R. 1987. Predicting intake and digestibility using mathematical models of ruminal function. J. Anim. Sci., 64(7):1548-58. 
MERTENS, D.R. Balancing carbohydrate in dairy rations. In: LARGE HERD DAIRY MANAGEMENT CONFERENCE, 1988, Ithaca. Proceedings... Ithaca: Cornell University, 1988. p.150-161.

MORAN, J.B. 1985. Comparative performance of five genotypes of Indonesian large ruminants. I. Effect of dietary quality on live weight and feed utilization. Aust. J. Agric. Res., 36(5):743-752.

NATIONAL RESEARCH COUNCIL - NRC. 1989. Nutrient requirements of dairy cattle. 6.rev.ed. Washington, D.C.: National Academy Press. 157p.

NATIONAL RESEARCH COUNCIL - NRC. 1996. Nutrients requirements of beef cattle. 7.rev.ed. Washington, D.C.: National Academy Press. 242p.

NUTT, B.G., HOLLOWAY, J.W., BUTTS JUNIOR, W.T. 1980. Relationship of rúmen capacity of mature angus cow to body measurements animal performance and forage consumption on pasture. J. Anim. Sci., 51(5):1168-1176.

RESENDE, F.D., QUEIROZ, A.C., OLIVEIRA, J.V. et al. 2001. Bovinos mestiços confinados alimentados com diferentes proporções de volumoso: concentrado. 1. Digestibilidade aparente dos nutrientes, ganho de peso e conversão alimentar. Rev. bras. zootec., 30(1):264-272.

RESENDE, F.D., QUEIROZ, A.C., FONTES, C.A.A. et al. 1994. Rações com diferentes níveis de fibra em detergente neutro na alimentação de bovídeos em confinamento. R. Soc. Bras. Zootec., 23(3):366-376.

RIBEIRO,T.R. Desempenho e qualidade da carcaça de bezerros holandeses alimentados com dietas contendo diferentes níveis de concentrado. Viçosa, MG: UFV, 1997. Dissertação(Mestrado em Zootecnia) - Universidade Federal de Viçosa, 1997.

RODRIGUES, L.R.R., FONTES, C.A.A., JORGE, A.M. et al. 1996. Consumo de rações contendo quatro níveis de concentrado por bovinos holandeses e nelore e por bubalinos. R. Soc. Bras. Zootec., 25(3):568-581.
STATISTICAL ANALYSIS SYSTEMS - SAS. 1992. User's Guide. Versão 6.0. Cary, NC: SAS Institute Inc. 1042p.

SILVA, D.J. 1990. Análise de alimentos (Métodos químicos e biológicos). 2.ed.Viçosa: UFV. 165p.

SNIFFEN,C.J., ROBINSON, P.H. 1987. Microbial growth and flow as influenced by dietary manipulation. J. Dairy Sci., $70(1): 425-441$.

THIAGO, L.R.L., GILL, M. Consumo voluntário de forragens por ruminantes: Mecanismo físico ou fisiológico? In: BOVINOCULTURA DE CORTE, 1990, Piracicaba: SBZ, FEALQ, 1990. p.1-9.

VAN SOEST, P.J. 1965. Symposium on factors influencing the voluntary intake in relation to chemical composition and digestibility. J. Anim. Sci., 24(2):834-843.

VAN SOEST, P.J. 1994. Nutritional ecology of the ruminant. 2.ed. London: Comstock Publishing Associates. 476p.

WALDO, D.R. 1986. Symposium: Forage utilization by lactating cow - Effect of forage quality on intake and forage-concentrate interactions. J. Dairy Sci., 69(2):617-631.

Recebido em: 28/02/00

Aceito em: 21/09/00 